\title{
$\begin{array}{ll}\text { Research Square } & \begin{array}{l}\text { Preprints are preliminary reports that have not undergone peer review. } \\ \text { They should not be considered conclusive, used to inform clinical practice, }\end{array} \\ \text { or referenced by the media as validated information. }\end{array}$
}

\section{Exposure-history Type and Characteristics of SARS- CoV-2 Infected Patients in Wuhan区Epicenter区 Neighboring Shaanxi Province of China}

\section{Zhangqian Chen}

Departement of infectious disease,Xijing Hospital, Air Force Military Medecal University

\section{Xiaoming Xu}

Department of Cardiology, Xijing Hospital, Air Force Military Medcical University

\section{Zhongshu Pu}

Department of infectious disease, the 940th hospital of joint logistics support force of the chunese people's liberation army

\section{Rui Yan}

Department of infectious disease, Xijing Hospital, Air Foece Military Medical University

\section{Jingwei Li}

Department of infectious disease, Xijing Hospital, Air Force military University

\section{Wei Zhang}

Department of infectious disease, Xijing Hospital, Air Force medical University

Jiuping Wang ( $\sim$ jpwang@fmmu.edu.cn )

Air Force Military Medical University https://orcid.org/0000-0001-8784-5978

\section{Research Article}

Keywords: SARS-CoV-2, Epidemiology, Characteristic, Exposure, Control

Posted Date: December 15th, 2020

DOl: https://doi.org/10.21203/rs.3.rs-126533/v1

License: (a) (1) This work is licensed under a Creative Commons Attribution 4.0 International License. Read Full License 


\section{Abstract \\ Background}

Since December 2019, an increasing number of SARS-CoV-2 infected pneumonia cases have been identified in Wuhan and its surrounding areas. As of March 2020 more than 150 countries, areas or territories have reported the infected cases of SARS-CoV-2 and still the infected number is rapidly increasing globally.

\section{Methods}

The whole outbreak period in Shaanxi Province (from Jan 23, 2020 to Feb 20, 2020) was split into two consecutive stages. Epidemiological feature like exposure-history type and characteristics of the confirmed SARS-CoV-2 infected patients in Shaanxi Province were analyzed.

\section{Results}

A total of 245 patients were confirmed with SARS-CoV-2 infection in Shaanxi Province, among whom 133 (54.29\%) were male and $112(45.71 \%)$ were female. The percentage of the imported cases dropped from $53.94 \%$ in earlier stage (Jan 23-Feb 5, 2020) to $16.25 \%$ in second stage (Feb 6-Feb 20, 2020) while that of cases with no definite exposure history and other types increased from $27.88-70.00 \%$.

\section{Conclusions}

As control measures were taken in earlier stage much less cases were confirmed in second stage. Our study contributes to the understanding of SARS-CoV-2 epidemiology and helps evaluate the effectiveness of control measures on local transmission.

\section{Introduction}

In December 2019, cases of pneumonia associated with a novel coronavirus (SARS-CoV-2; previously known as 2019-nCoV) emerged in Wuhan, Hubei Province. To date the virus has spread to more than 150 countries, areas or territories [1]. Earlier epidemiological studies have reached the consensus that the transportation between Wuhan (Epicenter) and other major cities in China played critical role in the domestic spreading of the SARS-CoV-2 infection in China [2-5]. Moreover the massive population migration before the Spring Festival has aggregated the spread of the virus. By the date of Feb 20, 2020 75,465 confirmed SARS-CoV-2 cases were reported in all 31 provinces of mainland China [6].

Shaanxi Province is an adjoining province northwest to Hubei Province, with a population of 38.64 million. The moderate travel load between the two provinces makes Shaanxi Province one ideal 
observation site for both epidemiology study and control-effectiveness observation of SARS-CoV-2 epidemic $[7,8]$. As the major attention was on clinical and major epidemiological features in Wuhan and surrounding areas of Hubei Province in earlier epidemic [9-11], other epidemiological features including patients' exposure-history type and characteristics in epic-center neighboring areas during the whole breakout period were rarely reported.

On January 19, 2020 the first confirmed case outside Hubei Province in China was reported in Shenzhen, Guangdong Province. Meanwhile with more exported cases outside Hubei Province in mainland China were reported, both nationwide and provincial measures were taken[12]. On Jan 22 China announced a travel quarantine of Wuhan and next day on Jan 23 Wuhan was locked down. By January 30 a total of 16 major cities in mainland China were included in the list of travel quarantine. The first confirmed case of SARS-CoV-2 infection was reported in Shaanxi Province on Jan 23, 2020. Control measures including case isolation, contact tracing, and surveillance were taken on the same day. On Jan 25 Provincial Primary Level (the highest level) Health Emergence Response was launched and travel quarantine was applied (restricted to Hubei Province). Further upgrading of travel quarantine (restricted to areas outside Shaanxi Province) was announced on January 31. On February 4 new series of measures including social distancing and community limitations were active in Shaanxi Province.

In this study retrospectively we performed a descriptive analysis on exposure-history type and characteristics of the confirmed SARS-CoV-2 infected patients and evaluated the control effects of provincial level measures on local transmission in epi-center neighboring Shaanxi Province.

\section{Methods}

\section{Settings}

Shaanxi Province $\left(31^{\circ} 42^{\prime} \mathrm{N}-39^{\circ} 35^{\prime} \mathrm{N}, 105^{\circ} 29^{\prime} \mathrm{E}-111^{\circ} 15^{\prime} \mathrm{E}\right)$ is located in northwestern China (Fig. 1). It is comprised of 11 prefecture-level cities, with a land area of $205,600 \mathrm{~km}^{2}$ and a population of 38.64 million in 2018[13]. With a population of 10, 00 million (2018) and land area of $10,108 \mathrm{~km}^{2}$, the population density of Xi'an is 989 persons $/ \mathrm{km}^{2}$. Xi'an is the regional center for Shaanxi Province and center city for northwestern China.

\section{Data collection and case definition}

Patients' data including exposure-history type and other characteristics including demographic features were obtained from public online data announced by Health Commission of Shaanxi Province (http://sxwjw.shaanxi.gov.cn/). As the public health is the major concern for both the study and publication, ethical approval is deemed unnecessary for the study.

The diagnosis of SARS-CoV-2 infection (or COVID-19) was established based on respiratory specimen detection by fluorescence quantitative polymerase chain reaction assay for SARS-CoV-2 nucleic acid combined with or without clinical characteristics and/or chest imaging throughout the outbreak period. 
Mapping

A spatial distribution map was made to analyze the spatial association of SARS-CoV-2 infection. The incidence rate (calculated by total infected number divided by the population of the prefecture-level city) in each prefecture-level city was mapped and different level of incidence rate was marked with a corresponding color on the city-level digital map.

\section{Statistical Analysis}

Categorical variables were presented as frequencies and proportions, and differences between groups were evaluated with chi-square test or Fisher's exact test. Continuous variables were reported as means with $95 \%$ confidence interval and were compared with Wilcoxon rank-sum test between groups. A twosided $P$ value of $\leq 0.05$ was considered to be statistically significant. All analyses were performed using SPSS.

\section{Results}

From Jan 23, 2020 to Feb 20, 2020 a total of 245 patients were confirmed with SARS-CoV-2 infection in Shaanxi Province. In general the average age of the confirmed patients was $46.02(95 \% \mathrm{Cl}, 43.96$ to 48.09) (Table 1). 133 (54.29\%) were male and 112 (45.71\%) were female (Table 1$) .5$ patients $(2.04 \%)$ were children under the age of 12 and the youngest was 3 years old (Table 1). 42 (17.14\%) and 5 (2.04\%) patients were above the age of 65 and 80 respectively, while the majority $(n=162,66.12 \%)$ were aged 30 to 65 years (Table 1 ). 
Table 1

Characteristics (gender and age) of all patients confirmed with SARS-CoV-2 infection in Shaanxi Province during the outbreak period

\begin{tabular}{|ll|}
\hline Charateristics & All patients $(\mathbf{N}=\mathbf{2 4 5})$ \\
\hline gender & \\
\hline Male-no./total no. (\%) & $133(54.29)$ \\
\hline Female-no./total no. (\%) & $112(45.71)$ \\
\hline Mean age-yr & 46.02 \\
\hline Age group-no./total no. (\%) & \\
\hline$<12 \mathrm{yr}$ & $5 / 245(2.04)$ \\
\hline $13-30 \mathrm{yr}$ & $36 / 245(14.69)$ \\
\hline $30-65 \mathrm{yr}$ & $162 / 245(66.12)$ \\
\hline $65-80 \mathrm{yr}$ & $37 / 245(15.10)$ \\
\hline$\geq 80 \mathrm{yr}$ & $5 / 245(2.04)$ \\
\hline
\end{tabular}

120 cases(48.98\%)were concentrated in Xi'an (Fig. 2), the capital city of Shaanxi Province and the main transport port (both flight and train). Other relatively high incident areas include Hanzhong and Ankang (Fig. 2), both of which were in southern part of Shaanxi Province and have closer transportation connections with Hubei Province by trains, buses, and private transportation.

To investigate the shift of the epidemic, the whole outbreak period was split into two consecutive stages: before Feb 6 since first reported confirmed case on January 23 (earlier stage, first 14 days period) and after Feb 5 till last reported confirmed case on February 20 (second stage, 15 days period) (Fig. 3).

89 (53.94\%) patients in earlier stage (Jan 23-Feb 5, 2020) had a history of living or travelling in either Wuhan or neighboring cities of Hubei Province after the onset of the SARS-CoV-2 epidemic (Imported cases) (Fig. 4). 24 (14.55\%) patients were local inhabitants confirmed to have direct contact with the imported cases (Local primary cases) (Fig. 4). 6 (3.65\%) patients were local inhabitants confirmed to have direct contact with the local primary cases (Local secondary cases) (Fig. 4). 46 patients (27.88\%) were patients with no definite exposure history and other types (Exposure indefinite and other types) (Fig. 4).

During the second stage (Feb 6-Feb 20, 2020) the percentage of the imported cases dropped from 53.94$16.25 \%$ while that of indefinite exposure history and other types increased from $27.88-70.00 \%$ (Fig. 4). Meanwhile the percentage of local primary and secondary cases decreased from 18.15-13.75\% (Fig. 4). 
The mean age of the confirmed patients in the second stage was 52.29 ( $95 \% \mathrm{Cl}, 48.57$ to 56.02 ), higher than that in earlier stage $(42.98,40.61$ to 45.35$)(P<0.001)$ (Table 2$)$. It was also noticed that percentage of female patients increased from $42.42 \%$ in earlier stage to $52.50 \%$ in second stage $(P>0.05)$ (Table 2$)$.

Table 2

Characteristics (age, gender, duration to confirm and exposure-history type) of the patients confirmed with SARS-CoV-2 infection in two consecutive stages in Shaanxi Province

\begin{tabular}{|llll|}
\hline Charateristics & $\begin{array}{l}\text { Jan 23-Feb 5 } \\
(\mathbf{N}=165)\end{array}$ & $\begin{array}{l}\text { Feb 6-Feb 20 } \\
(\mathbf{N}=80)\end{array}$ & Pvalue \\
\hline Age, mean & 42.98 & 52.29 & $<0.001$ \\
$(95 \%$ Cl)-year & $(40.61$ to 45.35$)$ & $(48.57$ to 56.02) & \\
\hline Female sex-no.(no./total, \%) & $70(70 / 165,42.42)$ & $42(42 / 80,52.50)$ & 0.1376 \\
\hline Duration to confirm, mean (95\% Cl) -day & 6.56 & 9.38 & $<0.001$ \\
& $(5.93$ to 7.19$)$ & $(8.33$ to 10.43) & \\
\hline Exposure-history type-no./total(\%) & & & \\
\hline Imported & $89 / 165(53.94)$ & $13 / 80(16.25)$ & \\
\hline Local primary & $24 / 165(14.55)$ & $8 / 80(10.00)$ & \\
\hline Local secondary & $6 / 165(3.64)$ & $3 / 80(3.75)$ & \\
\hline Indefinite exposure history and other types & $46 / 165(27.88)$ & $56 / 80(70.00)$ & \\
\hline
\end{tabular}

The mean duration from symptom onset to diagnosis (Duration to confirm) in earlier stage was 6.56 days ( $95 \% \mathrm{Cl}, 5.93$ to 7.19$)$, approximately 3 days shorter than that of the second stage $(9.38,8.33$ to 10.43$)(P$ $<0.001$ ) (Table 2). We noted that a total of 31 cases (18 in earlier stage and 13 in second stage) became symptomatic or asymptomatically confirmed during the quarantine observation period as close-contacts of the confirmed cases (due to lack of symptom or direct diagnosis post symptom onset these 31 cases were excluded from the calculation of the duration to confirm).

Obvious family clustering phenomenon was also observed, with a total of 117 cases clustered in 39 families (2-6 cases/cluster) and accounting for $43.67 \%$ of the total confirmed cases.

\section{Discussion}

As the control measures were taken during late-January in succession the effectiveness on local transmission of SARS-CoV-2 infection was demonstrated by the declining number of daily confirmed SARS-CoV-2 infected cases during mid-February in second stage.

From Jan 23 through Feb 5, 2020 the Hubei-area imported cases took the majority of the confirmed cases. However, as the epidemic was evolving more contact-origin unidentified cases, including cases 
with no definite exposure history were confirmed during the second stage (Feb 6, 2020 to Feb 20, 2020). On the one hand, the results demonstrated the effect of city knockdown and travel quarantine. On the other hand, the transition also suggested an increased risk for community or environmental transmission as the epidemic was evolving. Though some local primary and secondary cases were confirmed, no local third-generation cases were reported during the whole outbreak period. Moreover from Feb 20 to Mar 10, 2020 no new cases were confirmed in Shaanxi Province. The above results validated the timeliness and effectiveness of the control measures in response to SARS-CoV-2 epidemic in Shaanxi Province.

In terms of average age of the confirmed cases, our results were similar to those reported in other areas in mainland China $[14,15]$. The small number of infected children and absence of infant case was also consistent with previous reports $[16,17]$. It was speculated that the low rate of children and infant infection was due to a lower risk of exposure or difficulty in identification due to mildness or lack of their symptom $[18,19]$. However, we noted a lower percentage of old-age infected patients compared with the earlier report in Wuhan [9], which was related to the lower rate of mortality (one case in 245 by the date of March 10, 2020) in Shaanxi Province. The phenomenon of obvious family clustering observed in both Liu's and our study alarm us the high probability of intra-family transmission during the outbreak period [20].

As the imported cases were mostly migrant workers back for the celebration of Chinese Spring Festival, the lower average age and more male percentile in earlier stage was observed, which was consistent with the results in other provinces[14, 15]. With the continuous implementation of control measures mentioned above, a shortened span from symptom onset to diagnosis should be expected. However, the duration to confirm in second stage was 3 days longer than that in earlier stage. We speculated the epidemic evolvement of exposure type might be the cause of the delay in second period, as patients with no definite exposure history were more unlikely to be identified and hospitalized. Moreover the asymptomatic or mild-symptom cases were more likely to accumulate and be confirmed in the second stage, thus contributing to the observed longer duration to confirm.

Our study also demonstrated the spatial heterogeneity of SARS-CoV-2 infected cases in Shaanxi Province, as shown by the higher incident rate in central areas (capital city and its surrounding areas) and southern part (adjoining areas to Hubei) of the province. Factors like geographical distance, transport accessibility and economic activity all might account for this heterogeneity $[5,21]$. Districts that display high-level mutual communication with epic-center areas should adapt more comprehensive and proactive containing measures [22].

One limitation of our study is that the incubation period of SARS-CoV-2 infected patients in Shaanxi Province was not calculated due to lack of complete data and uncertainty of exact date concerning patients' exposure time.

\section{Conclusions}


In conclusion, we analyzed epidemiological feature like exposure-history and characteristics of SARSCoV-2 infected patients in Wuhan, Hubei neighboring Shaanxi Province during the whole outbreak period. From the view of public health's point the serial measures taken by local government in China like Shaanxi Province set an example for the world, given the abruptness of the epidemic and the pandemic situation globally[23, 24].

\section{Declarations}

\section{Ethical Approval and Consent to participate}

Not applicable.

\section{Authors' contributions}

Concept and design: Jiuping Wang and Zhangqian Chen. Acquisition, analysis, or interpretation of data: Zhangqian Chen, Xiaoming Xu, Zhongshu Pu, Jingwei Li, Rui Yan, and Wei Zhang. Drafting of the manuscript: Zhangqian Chen.

\section{Acknowledgement}

We would like to thank Health Commission of Shaanxi Province (http://sxwjw.shaanxi.gov.cn/) for the use of the data. We also thank Professor Daiming Fan and Professor Yongzhan Nie from the State key Laboratory of Cancer Biology, National Clinical Research Center for Digestive Diseases and Xijing Hospital of Digestive Disease for their supports.

\section{Funding}

This study was funded by the National Natural Science Foundation of China (grant 81903075).

\section{Competinginterests}

The authors declare that they have no conflict of interest.

\section{Consent for publication}

Not applicable.

\section{Availability of supporting data}

Patients' data including exposure-history type and other characteristics including demographic features were obtained from public online data announced by Health Commission of Shaanxi Province (http://sxwjw.shaanxi.gov.cn/).

\section{Authors' information}


${ }^{1}$ Department of Infectious Diseases, Xijing Hospital, Air Force Military Medical University, Xi'an, 710032, China. ${ }^{2}$ Department of Cardiology, Xijing Hospital, Air Force Military Medical University, Xi'an, 710032, China. ${ }^{3}$ Department of Infectious Disease, the 940th Hospital of Joint Logistics Support Force of the Chinese People's Liberation Army, Lanzhou, 730032, China

\section{References}

[1] Special Expert Group for Control of the Epidemic of Novel Coronavirus Pneumonia of the Chinese Preventive Medicine A. [An update on the epidemiological characteristics of novel coronavirus pneumoniaCOVID-19]. Zhonghua liu xing bing xue za zhi = Zhonghua liuxingbingxue zazhi 2020;41:13944.

[2] Zhao S, Zhuang Z, Ran J, Lin J, Yang G, Yang L, et al. The association between domestic train transportation and novel coronavirus (2019-nCoV) outbreak in China from 2019 to 2020: A data-driven correlational report. Travel medicine and infectious disease 2020:101568.

[3] Wilson ME, Chen LH. Travelers Give Wings to Novel Coronavirus (2019-nCoV). Journal of travel medicine 2020.

[4] Ai S, Wang Z. Traveling bands for the Keller-Segel model with population growth. Mathematical biosciences and engineering: MBE 2015;12:717-37.

[5] Wu JT, Leung K, Leung GM. Nowcasting and forecasting the potential domestic and international spread of the 2019-nCoV outbreak originating in Wuhan, China: a modelling study. Lancet 2020.

[6] Chinese Center For Disease Control and Prevention. Update on the novel coronavirus pneumonia outbreak (Feb 21, 2020). Available from: http://www.chinacdc.cn/jkzt/crb/zl/szkb_11803/jszl_11809/202002/t20200221_213490.html.

[7] Du Z, Wang L, Cauchemez S, Xu X, Wang X, Cowling BJ, et al. Risk for Transportation of 2019 Novel Coronavirus Disease from Wuhan to Other Cities in China. Emerging infectious diseases 2020;26.

[8] Fan C, Liu L, Guo W, Yang A, Ye C, Jilili M, et al. Prediction of Epidemic Spread of the 2019 Novel Coronavirus Driven by Spring Festival Transportation in China: A Population-Based Study. International journal of environmental research and public health 2020;17.

[9] Li Q, Guan X, Wu P, Wang X, Zhou L, Tong Y, et al. Early Transmission Dynamics in Wuhan, China, of Novel Coronavirus-Infected Pneumonia. The New England journal of medicine 2020.

[10] Huang C, Wang Y, Li X, Ren L, Zhao J, Hu Y, et al. Clinical features of patients infected with 2019 novel coronavirus in Wuhan, China. Lancet 2020;395:497-506. 
[11] Backer JA, Klinkenberg D, Wallinga J. Incubation period of 2019 novel coronavirus (2019-nCoV) infections among travellers from Wuhan, China, 20-28 January 2020. Euro surveillance : bulletin Europeen sur les maladies transmissibles = European communicable disease bulletin 2020;25.

[12] Deng SQ, Peng HJ. Characteristics of and Public Health Responses to the Coronavirus Disease 2019 Outbreak in China. Journal of clinical medicine 2020;9.

[13] Swerdlow DL, Finelli L. Preparation for Possible Sustained Transmission of 2019 Novel Coronavirus: Lessons From Previous Epidemics. Jama 2020.

[14] Guan WJ, Ni ZY, Hu Y, Liang WH, Ou CQ, He JX, et al. Clinical Characteristics of Coronavirus Disease 2019 in China. The New England journal of medicine 2020.

[15] Tian S, Hu N, Lou J, Chen K, Kang X, Xiang Z, et al. Characteristics of COVID-19 infection in Beijing. The Journal of infection 2020.

[16] Wei M, Yuan J, Liu Y, Fu T, Yu X, Zhang ZJ. Novel Coronavirus Infection in Hospitalized Infants Under 1 Year of Age in China. Jama 2020.

[17] Liu W, Zhang Q, Chen J, Xiang R, Song H, Shu S, et al. Detection of Covid-19 in Children in Early January 2020 in Wuhan, China. The New England journal of medicine 2020.

[18] Paules Cl, Marston HD, Fauci AS. Coronavirus Infections-More Than Just the Common Cold. Jama 2020.

[19] Del Rio C, Malani PN. 2019 Novel Coronavirus-Important Information for Clinicians. Jama 2020.

[20] Liu J, Liao X, Qian S, Yuan J, Wang F, Liu Y, et al. Community Transmission of Severe Acute Respiratory Syndrome Coronavirus 2, Shenzhen, China, 2020. Emerging infectious diseases 2020;26.

[21] Fan J, Liu X, Pan W, Douglas MW, Bao S. Epidemiology of 2019 Novel Coronavirus Disease-19 in Gansu Province, China, 2020. Emerging infectious diseases 2020;26.

[22] Zheng R, Xu Y, Wang W, Ning G, Bi Y. Spatial transmission of COVID-19 via public and private transportation in China. Travel medicine and infectious disease 2020:101626.

[23] Kinross P, Suetens C, Gomes Dias J, Alexakis L, Wijermans A, Colzani E, et al. Rapidly increasing cumulative incidence of coronavirus disease (COVID-19) in the European Union/European Economic Area and the United Kingdom, 1 January to 15 March 2020. Euro surveillance : bulletin Europeen sur les maladies transmissibles = European communicable disease bulletin 2020.

[24] Livingston E, Bucher K. Coronavirus Disease 2019 (COVID-19) in Italy. Jama 2020.

\section{Figures}




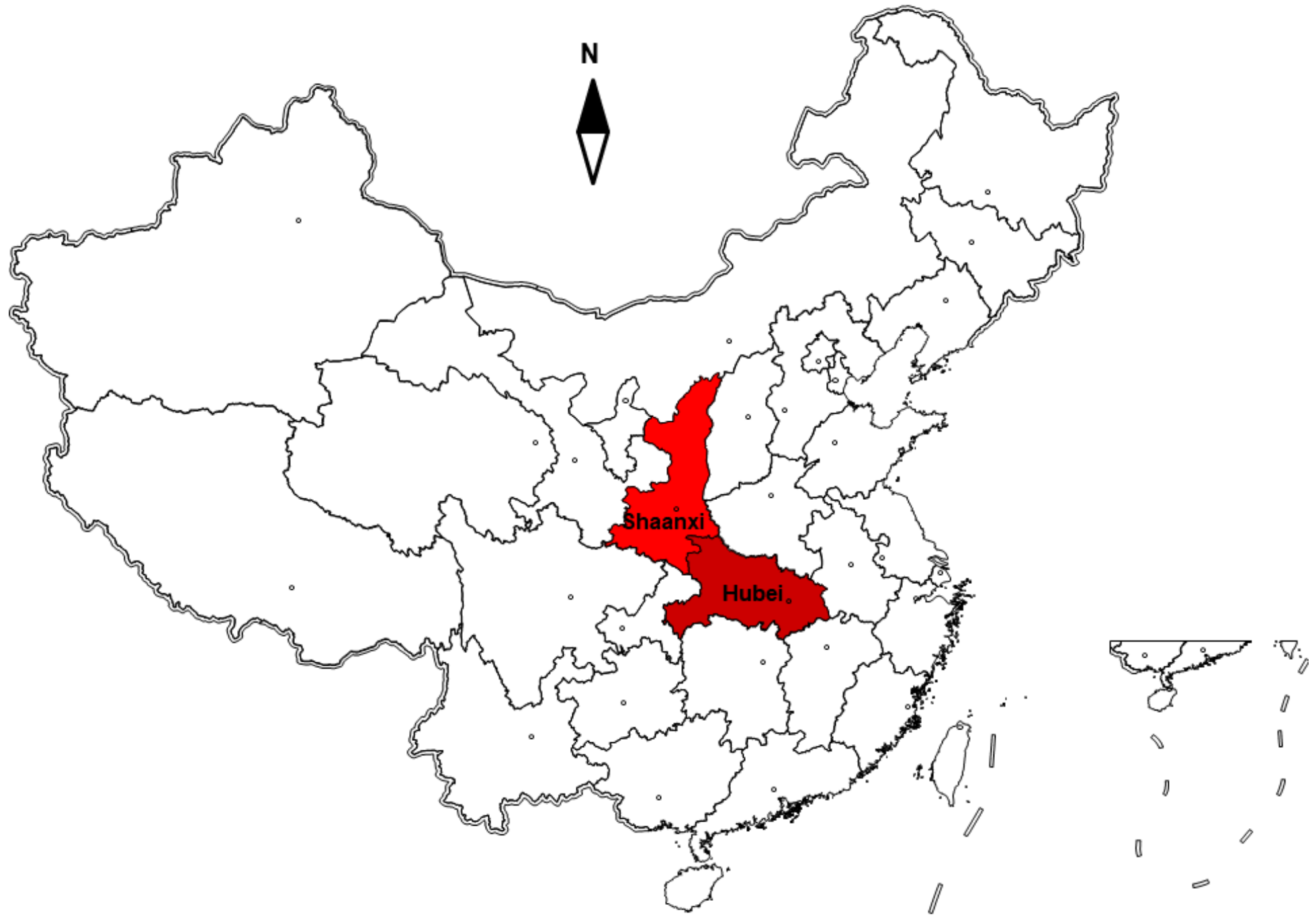

Figure 1

The location of Shaanxi and Hubei Province in China were marked with color. Circles indicate the capital cities. Note: The designations employed and the presentation of the material on this map do not imply the expression of any opinion whatsoever on the part of Research Square concerning the legal status of any country, territory, city or area or of its authorities, or concerning the delimitation of its frontiers or boundaries. This map has been provided by the authors. 


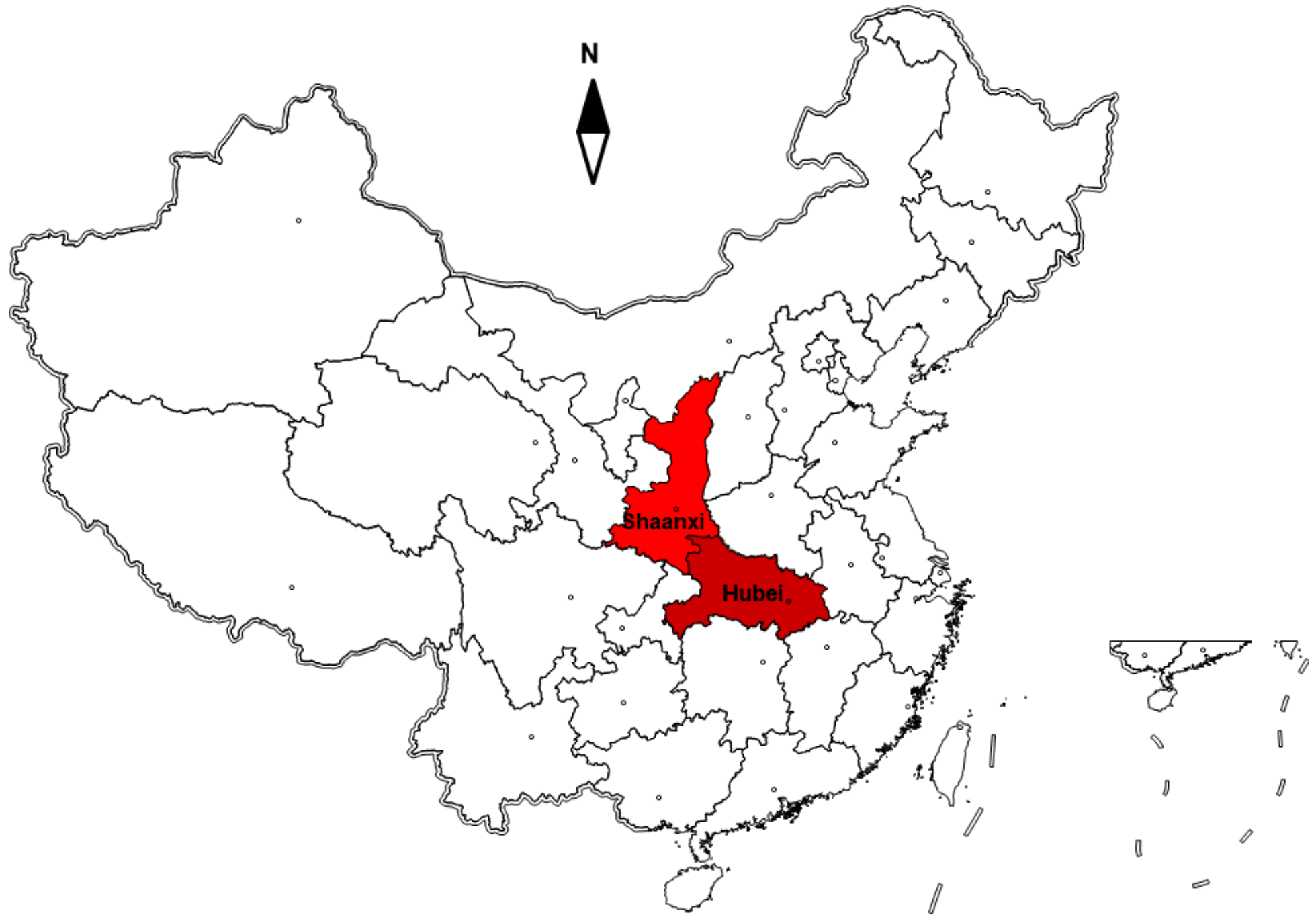

Figure 1

The location of Shaanxi and Hubei Province in China were marked with color. Circles indicate the capital cities. Note: The designations employed and the presentation of the material on this map do not imply the expression of any opinion whatsoever on the part of Research Square concerning the legal status of any country, territory, city or area or of its authorities, or concerning the delimitation of its frontiers or boundaries. This map has been provided by the authors. 
Infection rate,

persons $/ 10$ million
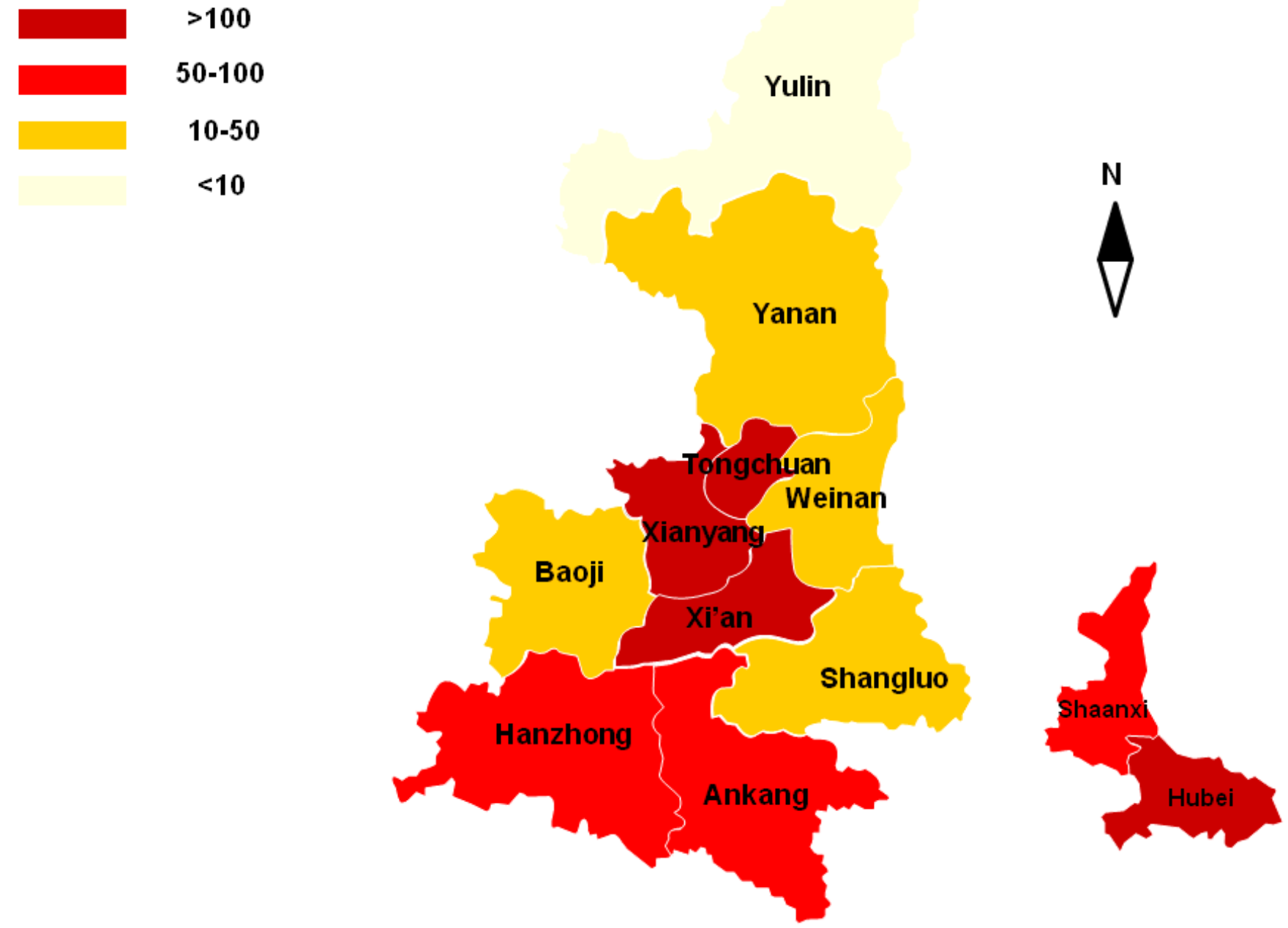

Figure 2

The SARS-CoV-2 infection incident rate in 10 prefecture-level cities of Shaanxi Province 
Infection rate,

persons $/ 10$ million
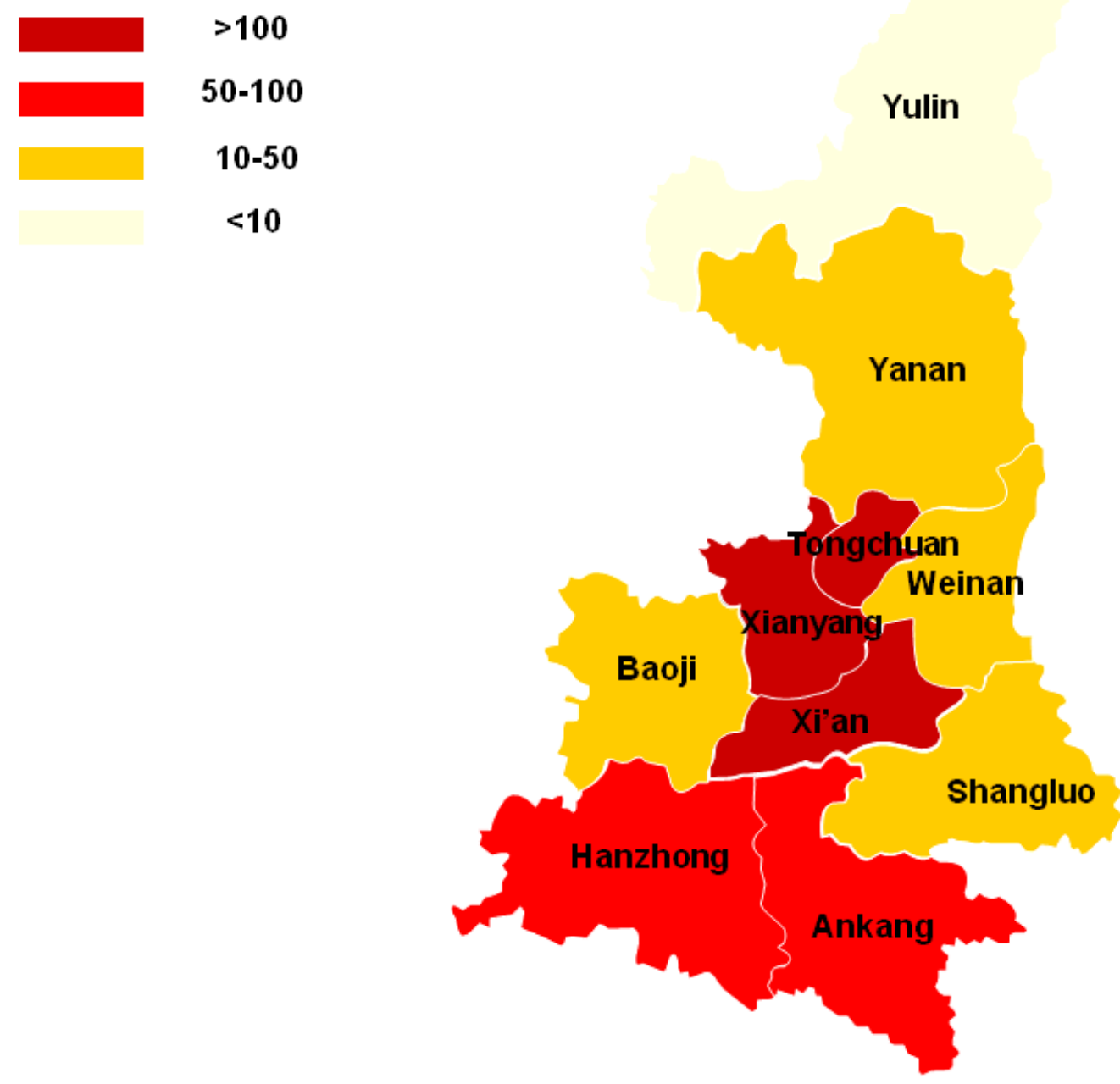

N
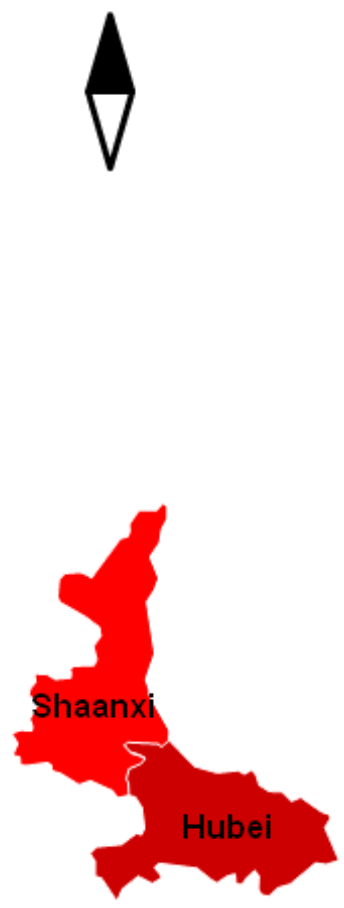

Figure 2

The SARS-CoV-2 infection incident rate in 10 prefecture-level cities of Shaanxi Province 


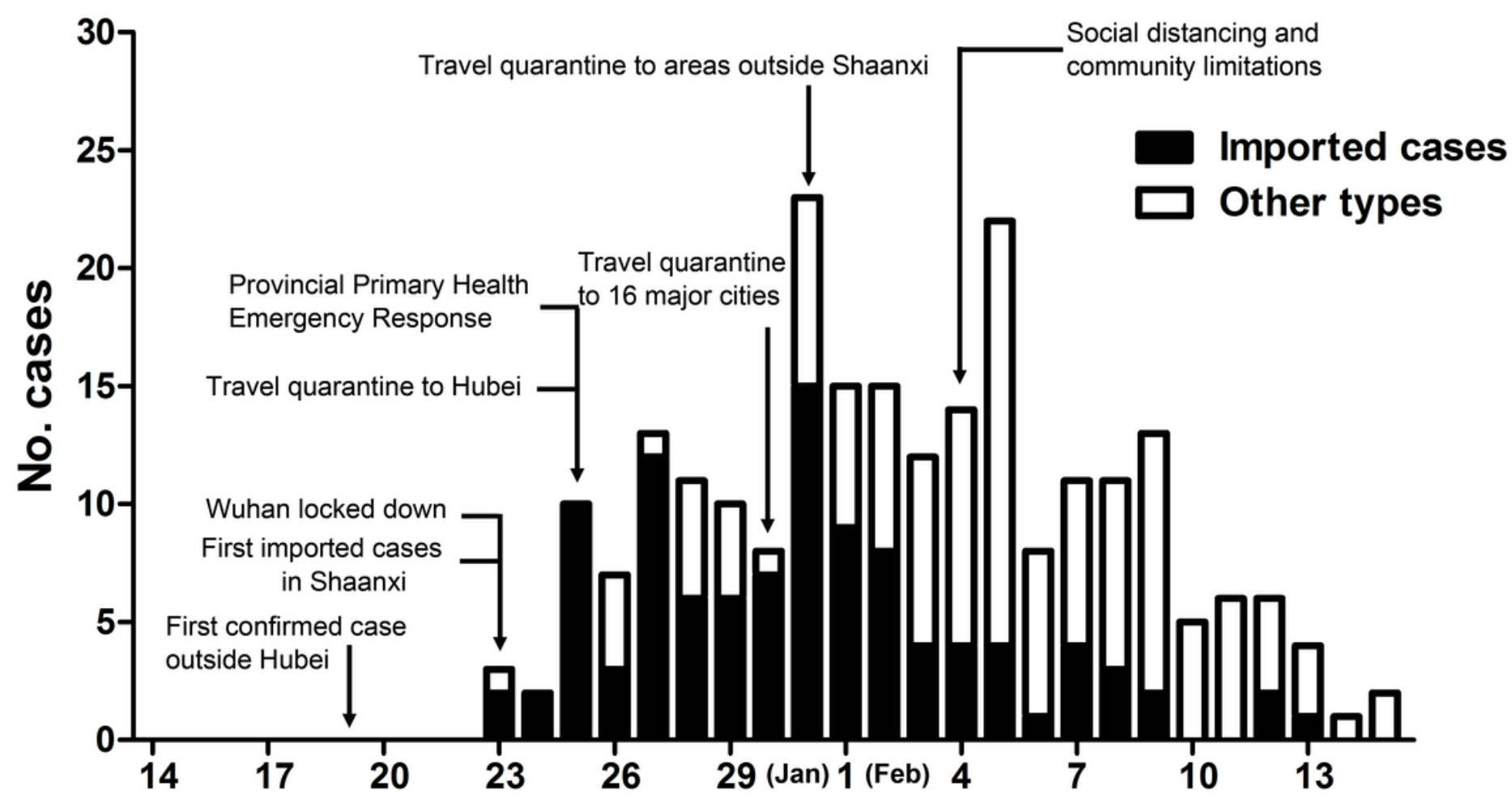

Figure 3

Major daily event and the number of daily confirmed SARS-CoV-2 infected cases in Shaanxi Province during the outbreak period

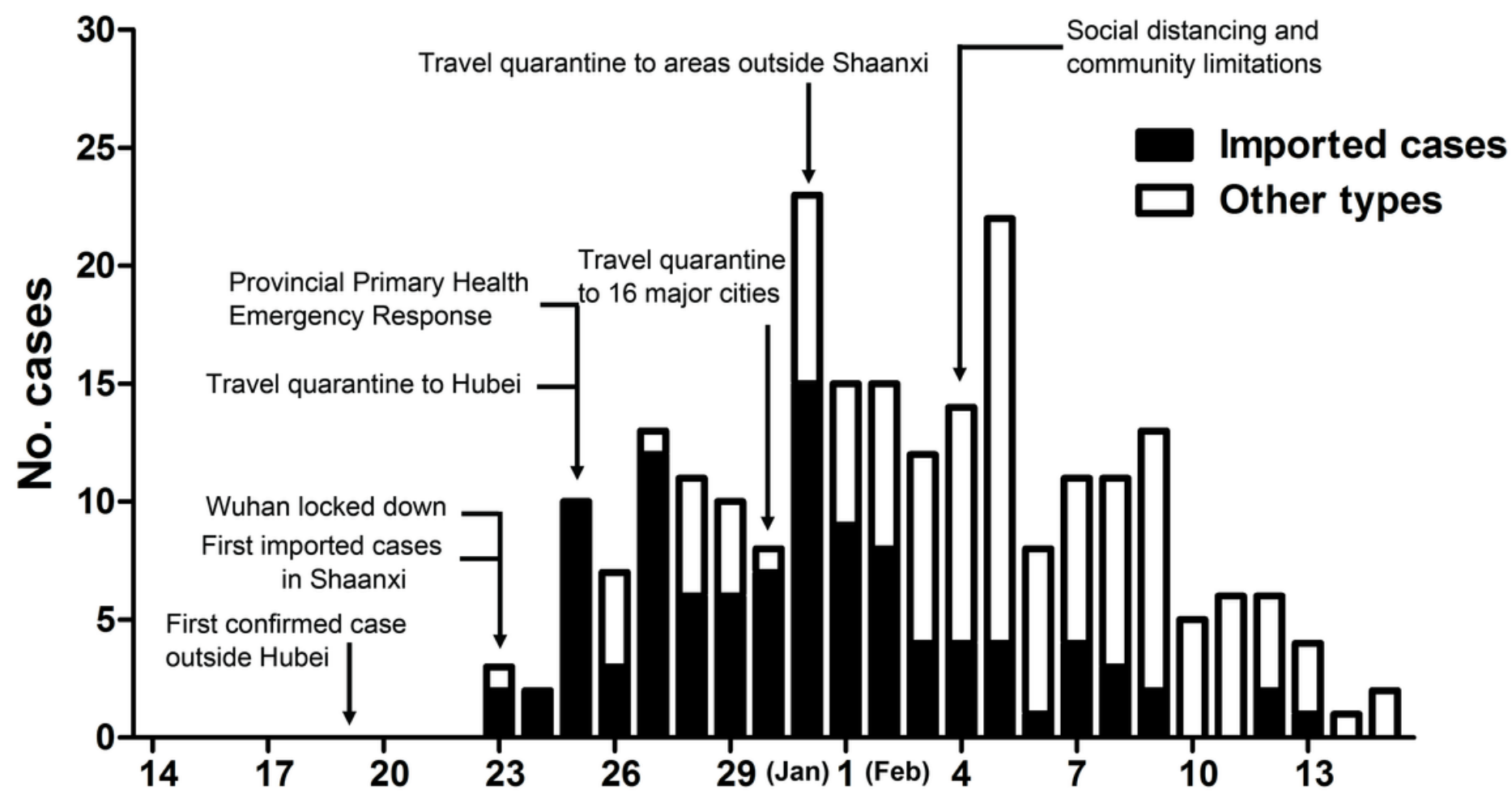


Figure 3

Major daily event and the number of daily confirmed SARS-CoV-2 infected cases in Shaanxi Province during the outbreak period

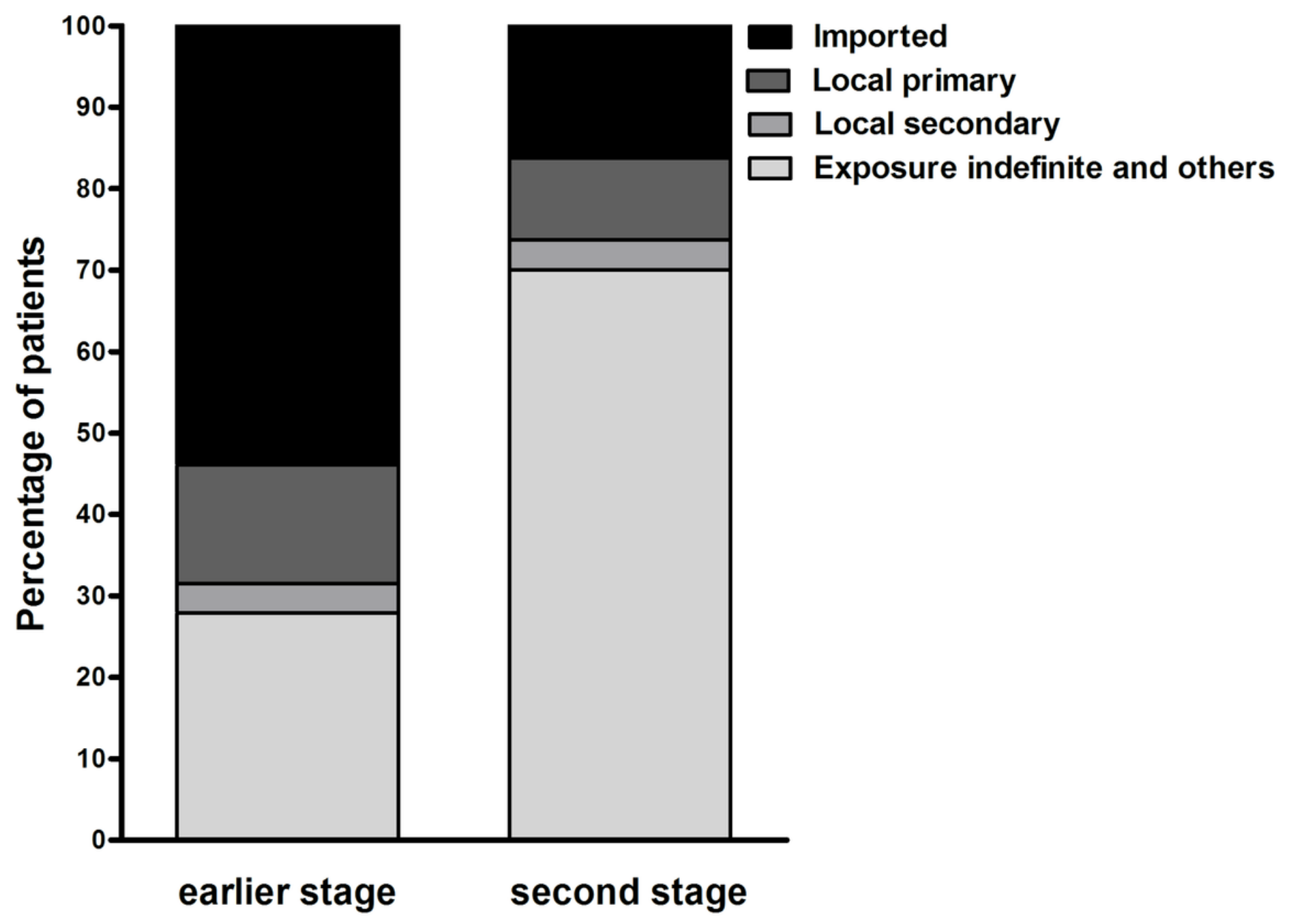

Figure 4

The percentage of the confirmed SARS-CoV-2 infected cases with different exposure-history type in Shaanxi Province in earlier stage (Jan 23 to Feb 5, 2020) and second stage (Feb 6 to Feb 20, 2020) 


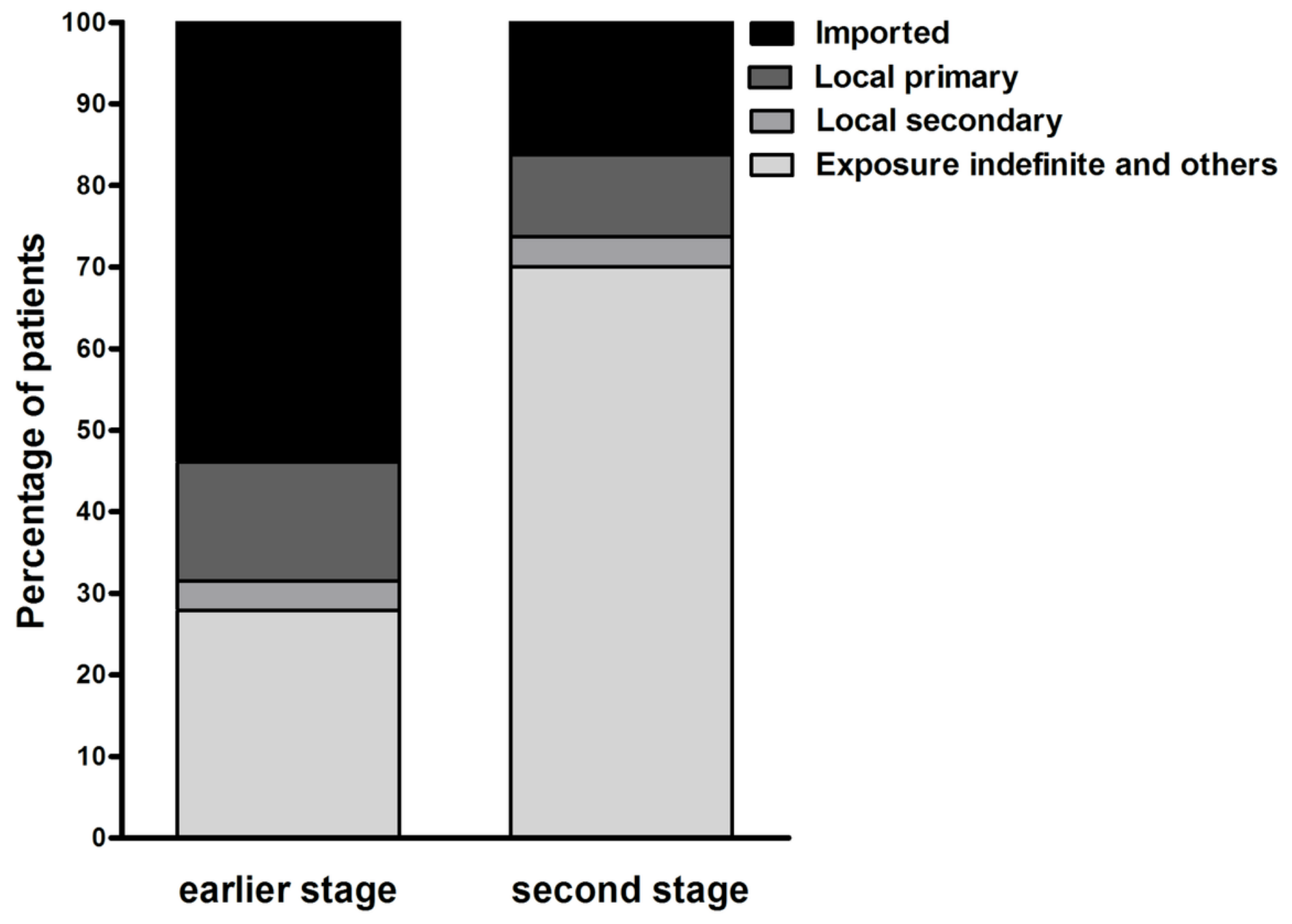

Figure 4

The percentage of the confirmed SARS-CoV-2 infected cases with different exposure-history type in Shaanxi Province in earlier stage (Jan 23 to Feb 5, 2020) and second stage (Feb 6 to Feb 20, 2020)

\section{Supplementary Files}

This is a list of supplementary files associated with this preprint. Click to download.

- data1.xlsx

- data1.xIsx

- data2.xIsx 
- data2.xlsx

Page 18/18 